ARTIGO ORIGINAL

ORIGINAL ARTICLE

\section{Custo-efetividade de alteplase no tratamento de acidente vascular cerebral isquêmico até 4,5 horas após início dos sintomas: perspectiva do Sistema Único de Saúde do Brasil (SUS)}

\author{
Cost-effectiveness of alteplase for treatment of ischemic \\ stroke up to 4.5 hours after the onset of symptoms: a \\ Brazilian Public Health System (SUS) perspective \\ Daniela Barbosa Campos', Sheila Cristina Ouriques Martins², \\ Juliana Safanelli³, Natália Bolzachini Santoni', Anna Rita Aguirre', \\ Miriam Allein Zago Marcolino,5, Rodrigo Antonini Ribeiro 5,6 \\ DOI: $10.21115 / J B E S . v 12 . n 3 . p 241-54$
}

\section{Palavras-chave}

alteplase, ativador de plasminogênio tecidual, Sistema Único de Saúde, análise de custo-efetividade, acidente vascular cerebral

\section{Keywords}

alteplase, tissue plasminogen activator, Unified Health System, cost-effectiveness analysis, stroke

\section{RESUMO}

Objetivo: Analisar o custo-efetividade da trombólise com alteplase no tratamento de acidente vascular isquêmico (AVCi) agudo em até 4,5 horas após início dos sintomas em comparação com tratamento clínico conservador, sob a perspectiva do Sistema Único de Saúde (SUS) no Brasil. Métodos: Construiu-se um modelo de Markov para simular o tratamento de AVCi agudo e suas consequências em curto e longo prazo. Foram conduzidas análises de custo-efetividade (anos de vida ganhos, AVG) e custo-utilidade (anos de vida ajustados pela qualidade de vida, QALY), considerando um horizonte temporal de tempo de vida. Parâmetros de eficácia e segurança foram obtidos em uma metanálise de dados individuais, considerando tratamento em até 3 horas e 3-4,5 horas. Os custos agudos e crônicos foram obtidos por análise secundária de dados de um hospital público brasileiro e expressos em reais $(R \$)$. Foram conduzidas análises de sensibilidade determinística e probabilística. Utilizou-se como limiar de disposição a pagar (LDP) 1 PIB (produto interno bruto) per capita para 2019 no Brasil (R\$31.833,50). Resultados: $O$ tratamento com alteplase vs. conservador resultou em incremento de 0,22 AVG, 0,32 QALY e R\$ 4.320,12 em custo, com razão de custo-efetividade incremental (RCEI) estimada em R\$19.996,43/AVG e R\$13.383,64/QALY. Ambas as estimativas foram mais sensíveis a variações na efetividade e nos custos de tratamento agudo com alteplase. Para RCEI/AVG e RCEI/ QALY, 70,7\% e 93,1\% das simulações na análise de sensibilidade probabilística estavam abaixo do LDP, respectivamente. Conclusões: $O$ tratamento com alteplase até 4,5 horas após o início dos sintomas tem elevada probabilidade de ser custo-efetivo na perspectiva do SUS.

\section{ABSTRACT}

Objective: To assess the cost-effectiveness of thrombolysis with alteplase for the treatment of acute ischemic stroke up to 4.5 hours after the onset of symptoms as compared to conservative medical treatment from the perspective of the Brazilian Public Health System. Methods: A Markov model was used to simulate the treatment of acute stroke and the associated short- and long-term

Recebido em: 30/10/2020. Aprovado para publicação em: 15/11/2020.

1. Boehringer Ingelheim do Brasil Química e Farmacêutica Ltda., São Paulo, SP, Brasil.

2. Hospital Moinhos de Vento, Porto Alegre, RS, Brasil.

3. Registro de AVC de Joinville, Joinville, SC, Brasil.

4. Programa de Pós-Graduação em Epidemiologia, Universidade Federal do Rio Grande do Sul, Porto Alegre, RS, Brasil. 5. Instituto Nacional de Ciência e Tecnologia/Instituto de Avaliação de Tecnologia em Saúde - INCT/IATS (CNPQ 465518/2014-1), Universidade Federal do Rio Grande do Sul, Porto Alegre, RS, Brasil.

6. HTAnalyze Consultoria e Treinamento, Porto Alegre, RS, Brasil.

Fonte de financiamento: Este estudo foi financiado pela Boehringer Ingelheim do Brasil, instituição onde o trabalho foi executado.

Congresso: Este estudo foi aceito para apresentação em formato de pôster no Congresso Virtual ISPOR Europa 2020. Conflitos de interesses: Alguns dos autores são funcionários da empresa produtora da tecnologia avaliada.

Autor correspondente: Daniela Barbosa Campos. Av. das Nações Unidas, 14.171, Vila Gertrudes, São Paulo, SP, Brasil. CEP: 04794-000. Telefone: +55 (11) 96170-3377. E-mail: daniela.campos@boehringer-ingelheim.com 
consequences. Cost-effectiveness (life-years gained, LYG) and cost-utility (quality-adjusted life years, QALY) analyses were performed considering a lifetime horizon. Efficacy and safety parameters were obtained from a meta-analysis of individual data, considering treatment within 3 hours and 3-4.5 hours after the onset of symptoms. Acute and chronic costs were derived from a secondary analysis of data obtained from a Brazilian public hospital and expressed in Brazilian reais (R\$). Probabilistic and deterministic sensitivity analyses were performed. The willingness to pay threshold (WPT) was established as 1 GDP per capita for 2019 in Brazil (R\$ 31,833.50). Results: Treatment with alteplase vs. conservative medical treatment was associated with an increase of 0.22 in LYG, 0.32 in QALY, and R\$ 4,320.12 in cost. The incremental cost-effectiveness ratio (ICER) was estimated as R\$19,996.43/LYG and $R \$ 13,383.64 / Q A L Y$. Variations in effectiveness and costs of acute alteplase treatment had the greatest impact on sensitivity analyses. Considering ICER/LYG and ICER /QALY, 70.7\% and 93.1\% of the simulations in probabilistic sensitivity analysis were below the WPT, respectively. Conclusions: Treatment with alteplase up to 4.5 hours after the onset of symptoms has a high probability of being cost-effective from the perspective of the Brazilian Public Health System.

\section{Introdução}

No Brasil, apesar da redução na mortalidade cardiovascular registrada entre 1992 e 2016 - a redução mais acentuada nas taxas padronizadas por idade em todas as categorias de doenças cardiovasculares no grupo de países que compõem o BRICS (Zou et al., 2020) -, as doenças cardíacas isquêmicas ainda representam a maior causa de mortalidade no país, tanto em homens quanto mulheres nas faixas etárias a partir de 30 anos (Brasil, 2019b). Da mesma forma, permanece elevado o impacto da doença cerebrovascular: o acidente vascular cerebral (AVC), apareceu, em 2016, como segundo no ranking das principais causas de óbito entre mulheres de todas as regiões e entre homens do Sul e do Sudeste na faixa de 30 a 69 anos. Nesse ano, conforme dados do estudo Global Burden of Disease (GBD), o Brasil registrou 107.258 mortes por AVC, das quais 66.261, ou 62\%, resultaram de AVC isquêmico (AVCi) (de Santana et al., 2018). Dados de mortalidade no Brasil em 2018 e 2019 também colocam as doenças cerebrovasculares como segunda causa de óbito mais frequente, inferior apenas à mortalidade por doenças isquêmicas do coração (Brasil, 2020).

Além da mortalidade, o AVCi tem importante impacto econômico e social. Conforme o Ministério da Saúde, a maior parte dos sobreviventes de AVC no país precisarão de reabilitação para sequelas neurológicas, com aproximadamente 70\% não retornando ao trabalho (Brasil, 2012). Em 2016, a taxa de anos de vida perdidos por incapacidade (DALYS) por AVCi foi de 1.215,72/100.000 habitantes na faixa economicamente ativa de 50 a 69 anos, independentemente de sexo, e a taxa de anos vividos com incapacidade (YLD) nesse mesmo grupo etário foi de 157,01/100.000. Na população acima de 70 anos, que cresce no Brasil com o processo de transição demográfica e na qual a recuperação funcional é mais difícil, foram registradas, em 2016, taxas de DALY de 5.393,9/100.000 e de YLD de 681,21/100.000 (de Santana et al., 2018) por AVCi. Evidências de outros países (Bugarski Ignjatovic et al., 2015) mostram comprometimento cognitivo em até $90 \%$ dos pacientes nas primeiras semanas após o AVC, incluindo diminuição na atenção, na capacidade de fala/linguagem e em funções executivas, mesmo na presença de recuperação satisfatória da capacidade funcional. Um estudo realizado na Suécia (Ullberg et al., 2015) mostrou ainda uma deterioração funcional (maior dependência na realização de atividades do dia a dia) em sobreviventes de AVC até 12 meses após o evento.

O tratamento do AVCi envolve, além de medidas conservadoras (monitoramento da evolução natural do quadro clínico e medidas de suporte), a trombólise intravenosa com alteplase na fase aguda, dentro de uma estreita janela terapêutica após o início dos sinais e sintomas clínicos. Inicialmente estabelecida como sendo de 3 horas (National Institute of Neurological Disorders and Stroke rt-PA Stroke Study Group, 1995), essa janela terapêutica foi posteriormente ampliada para 4,5 horas (Lansberg et al., 2009). De fato, as diretrizes de tratamento do AVCi no Sistema Único Saúde (SUS) (Brasil, 2012) reconhecem como "fase aguda" o período de 4,5 horas após início dos sinais e sintomas, recomendando o tratamento com alteplase nesse intervalo. Uma análise anterior (Araújo et al., 2010) a partir da perspectiva do SUS já demonstrou o custo-efetividade para tratamento com alteplase em até 3 horas. Contudo, dado o protocolo utilizado atualmente no país, assim como as evidências que indicam que quanto mais precoce o tratamento, melhores os resultados para o paciente (Whiteley et al., 2016), é fundamental avaliar também o custo-efetividade do tratamento com alteplase conforme preconizado atualmente pelo Ministério da Saúde.

Sendo assim, o objetivo do presente estudo foi realizar uma análise de custo-efetividade e custo-utilidade da trombólise com alteplase no tratamento de AVCi agudo em até 4,5 horas após o início dos sinais e sintomas, em comparação com tratamento conservador, considerando suas consequências em curto e longo prazo, sob a perspectiva do SUS do Brasil.

\section{Métodos}

\section{População-alvo}

A população-alvo deste estudo são pacientes com primeiro evento de AVCi agudo, elegíveis para trombólise conforme 
Protocolo Clínico e Diretrizes Terapêuticas do SUS (Brasil, 2012) e bula do medicamento [Actilyse (alteplase). Bula profissional. Boehringer Ingelheim. Anvisa; 2019]: pacientes de ambos os sexos com AVCi agudo confirmado por neurologista, apresentando sinais e sintomas há 4,5 horas ou menos até a infusão do medicamento, com idade acima de 18 anos e sem sinais de hemorragia em exames de tomografia computadorizada ou ressonância magnética.

\section{Fontes de eficácia e segurança}

O modelo desenvolvido para análise de custo-efetividade e custo-utilidade compara duas opções de tratamento: trombólise com alteplase 0,9 mg/kg (máximo de $90 \mathrm{mg}$ ), por via intravenosa, com 10\% da dose aplicada em bolus e o restante continuamente ao longo de 60 minutos, ou tratamento clínico conservador.

Foi conduzida uma busca na literatura científica por revisões sistemáticas prévias que investigassem a eficácia e a segurança de alteplase no tratamento de AVCi agudo até 4,5 horas após o início dos sinais e sintomas. As buscas por revisões sistemáticas publicadas até 13/12/2019 foram conduzidas no Clinical Queries do PubMed. A estratégia de busca está apresentada na Tabela 1.

A busca identificou 389 registros. Dois estudos foram ainda identificados nas listas de referências das publicações incluídas e mediante busca no PubMed sem utilização do filtro de revisões sistemáticas. Após seleção de títulos e resumos, 15 publicações completas foram avaliadas. Duas publicações de uma metanálise com dados de pacientes individuais foram selecionadas como fonte de eficácia e segurança para o modelo (Emberson et al., 2014, Whiteley et al., 2016).

Essas metanálises incluíram dados de 6.765 pacientes de nove ensaios clínicos randomizados de fase 3, comparando alteplase com placebo ou controle aberto. Os ensaios clínicos avaliaram o tratamento com alteplase em diferentes intervalos de tempo até o tratamento. Para o presente estudo, foram considerados apenas os resultados que incluíram pacientes tratados em até 4,5 horas, subdividindo em pacientes tratados em até 3 horas e de 3 a 4,5 horas, considerando que a eficácia de alteplase apresenta relação linear inversa com o tempo até o tratamento $(p=0,016)$ (Emberson et al., 2014). As metanálises foram conduzidas em modelos de regressão logística estratificadas por estudo e ajustadas por tempo até tratamento, gravidade do AVC na apresentação e idade dos pacientes.

As probabilidades de eventos no grupo controle e a medida de efeito do tratamento com alteplase reportadas nas metanálises utilizadas no modelo estão apresentadas na Tabela 2.

Nas metanálises, não são reportadas medidas de efeito de alteplase para pacientes nos níveis de incapacidade mRS 2-3 e 4-5. Assim, a proporção de pacientes com mRS 2-3 no grupo com mRS 2-5 (45,8\%) foi estimada a partir da proporção de pacientes em cada categoria de mRS no grupo controle relatada na publicação de Whiteley et al. (2016). Essa proporção foi utilizada para estimar a probabilidade de transição para mRS 2-3 em ambos os braços de comparação (não assumindo benefício de alteplase nessa distribuição). Foram considerados para a presente análise ciclos com duração de três meses no primeiro ano do modelo. Depois disso, os ciclos passaram a ter duração de um ano. Ao final do primeiro ciclo, pacientes que não fossem destinados para mRS 0-1, mRS 2-3 ou morte entraram no estado mRS 4-5.

\section{Desenho do modelo}

Foi construído um modelo de Markov para simulação do tratamento de AVCi agudo e seguimento desses pacientes ao longo do tempo, para estimativa dos custos e dos desfechos dos tratamentos. Foram conduzidas análises de custo-efetividade, com desfecho medido em anos de vida ganhos (AVG) e custo-utilidade, com desfecho medido em anos de vida ajustados pela qualidade (QALY), considerando um horizonte temporal de tempo de vida toda.

Tabela 1. Estratégia de busca utilizada na revisão da literatura sobre eficácia e segurança de alteplase no tratamento de acidente vascular cerebral isquêmico

\begin{tabular}{|c|c|c|}
\hline Identificador & Estratégia & Hits \\
\hline \#1 & "Thrombolytic Therapy"[MeSH] OR "Thrombolytic Therapy" OR "Fibrinolytic" OR "Thrombolysis" & 75.187 \\
\hline \#2 & $\begin{array}{l}\text { "Tissue Plasminogen Activator"[MeSH] OR "Tissue Plasminogen Activator" OR ("Plasminogen Activator, Tissue") } \\
\text { OR ("Tissue Activator D 44") OR ("Tisokinase") OR ("Tissue-Type Plasminogen Activator") OR ("Tissue Type } \\
\text { Plasminogen Activator") OR ("TTPA") OR ("T Plasminogen Activator") OR ("Alteplase") OR ("Plasminogen Activator, } \\
\text { Tissue Type") OR ("Activase") OR ("Actilyse") OR ("alteplase") OR ("tPA") }\end{array}$ & 43.254 \\
\hline \#3 & (\#1 OR \#2) & 102.147 \\
\hline \#4 & Stroke[MeSH] OR "Stroke" & 324.713 \\
\hline \#5 & (\#3 AND \#4) & 19.445 \\
\hline \#6 & "systematic"[sb] & 144.239 \\
\hline \#7 & (\#5 AND \#6) & 389 \\
\hline
\end{tabular}


Tabela 2. Desfechos de eficácia e segurança utilizados no modelo de alteplase no tratamento do acidente vascular cerebral isquêmico

\begin{tabular}{|c|c|c|c|}
\hline Desfecho & Controle (\%) & Alteplase OR (IC 95\%) & Fonte \\
\hline HIC sintomática $(0-4,5 h)^{*}$ & $1,36 \%$ & $5,55(4,01-7,7)$ & Whiteley et al., 2016 \\
\hline \multicolumn{4}{|l|}{ HIC fatal } \\
\hline $0-3 h$ & $0,4 \%$ & $10,86(2,54-46,41)$ & Emberson et al., 2014 \\
\hline $3-4,5 h$ & $0,4 \%$ & $5,63(2,49-12,76)$ & Emberson et al., 2014 \\
\hline \multicolumn{4}{|l|}{ Desfecho em 3 mesest } \\
\hline \multicolumn{4}{|l|}{ mRS 0-1 } \\
\hline $0-3 h$ & $27,6 \%$ & $1,75(1,35-2,27)$ & Emberson et al., 2014 \\
\hline $3-4,5 h$ & $27,6 \%$ & $1,26(1,05-1,51)$ & Emberson et al., 2014 \\
\hline \multicolumn{4}{|l|}{ Morte } \\
\hline $0-3 h$ & $18 \%$ & $1,00(0,81-1,24)+\dagger$ & Emberson et al., 2014 \\
\hline $3-4,5 h$ & & $1,14(0,95-1,36)+\dagger$ & Emberson et al., 2014 \\
\hline
\end{tabular}

Nota: *Estudo não apresenta OR separado por tempo até tratamento, utilizado OR geral de alteplase vs. placebo. †Modified Rankin scale (mRS): 0-1 - desfecho ótimo (paciente livre de sintomas ou sintomas residuais sem perda de atividade); 5-6 - desfecho muito ruim (paciente acamado ou óbito) aos 3-6 meses. †† Hazard ratio (IC95\%). HIC: hemorragia intracraniana. IC: intervalo de confiança.

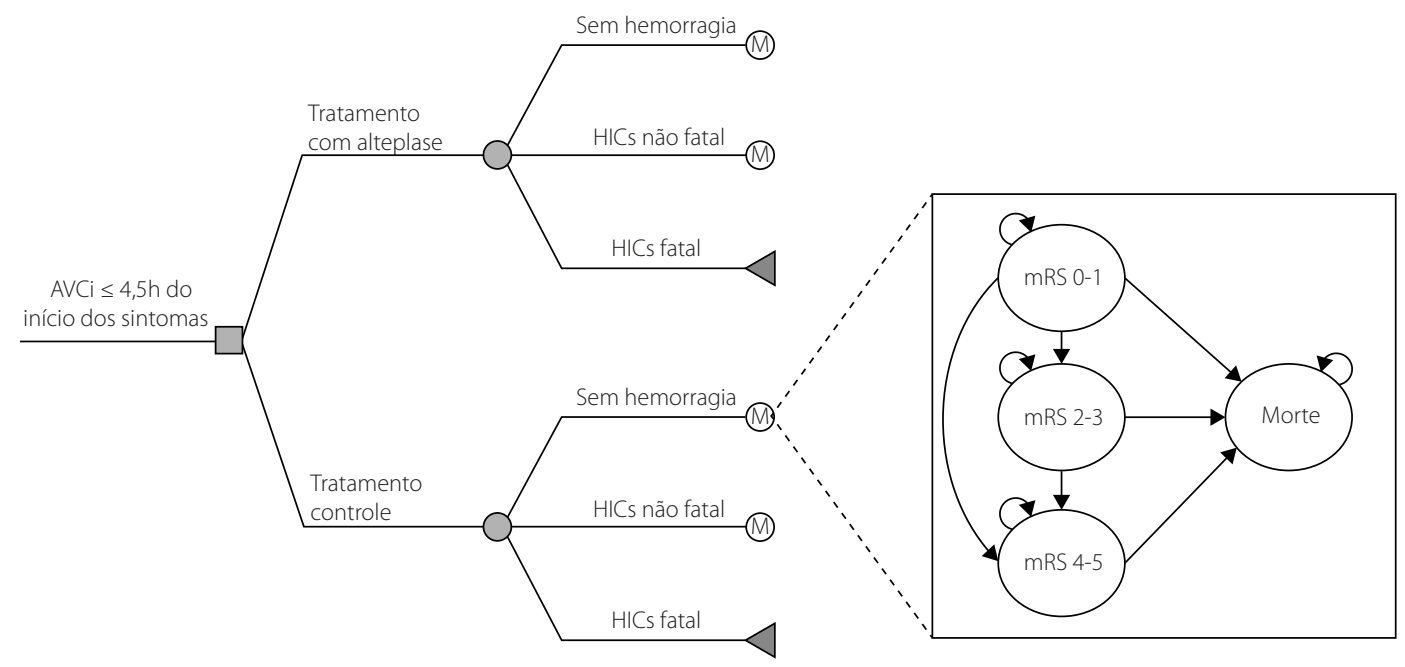

AVCi: acidente vascular isquêmico; HICs: hemorragia intracraniana sintomática; mRS: escala de Rankin modificada.

Figura 1. Modelo de Markov para simulação do tratamento de AVCi agudo e seguimento.

O desenho esquemático do modelo está apresentado na Figura 1. Pacientes com AVCi, elegíveis para trombólise em até 4,5 h do início dos sinais e sintomas, poderiam receber tratamento clínico convencional ou trombólise. Foram utilizados parâmetros distintos, de acordo com o tempo até o tratamento (0-3 h ou 3-4,5 h), para o grupo que recebeu trombólise. Assim, o resultado agrupado para o braço trombólise é ponderado pela proporção de pacientes tratados em cada período, conforme descrito em coorte de pacientes atendidos em hospital público do Brasil, onde, entre pacientes tratados em 0-4,5 h, 50,5\% foram tratados em até 3 h e 49,5\% foram tratados em 3-4,5 h (Cougo-Pinto et al., 2012).

Após o tratamento, os pacientes poderiam apresentar hemorragia intracraniana sintomática (HICs) fatal ou não fatal.
Os sobreviventes eram distribuídos ao final do primeiro ciclo entre quatro estados, representando diferentes níveis de incapacidade (avaliada pela escala de Rankin modificada mRS: mRS 0-1, 2-3, 4-5) e morte, estrutura adotada em modelo de avaliação de custo-utilidade para alteplase prévio (Pan et al., 2014).

Ao final de cada ciclo, os pacientes poderiam permanecer no mesmo nível de incapacidade, progredir ou morrer. A progressão para níveis piores de incapacidade ocorreria por reincidência de AVC. Pacientes com AVC reincidente receberiam tratamento clínico sem trombólise, e foram distribuídos igualmente entre os níveis de incapacidade, conforme modelos de custo-efetividade de alteplase prévios (Fagan et al., 1998; Sinclair et al., 2001; Sandercock et al., 2004; Tung et al., 
2011; Boudreau et al., 2013; Pan et al., 2014). A morte poderia ser causada por AVC reincidente ou por outras causas. As taxas de mortalidade por todas as causas, de acordo com idade e sexo, foram obtidas diretamente das Tábuas de Mortalidade do Instituto Brasileiro de Geografia e Estatística (IBGE) de 2018 para idades abaixo de 80 anos e da extrapolação delas para as idades acima de 80 anos. As Tábuas são utilizadas pelo Ministério da Previdência Social (MPS) para avaliações atuariais que tratem dos benefícios de segurados válidos ou inválidos (Brasil, 2019b; Castro, 2015).

Assumiu-se que os pacientes apresentam risco aumentado de mortalidade por todas as causas de acordo com o nível de incapacidade avaliada pela mRS (Fang et al., 2014). Para prevenir dupla contagem de morte por AVC reincidente na mortalidade por todas as causas, foi estimada a proporção de morte por AVC em comparação com o total de mortes nos registros do Sistema de Informações Hospitalares do SUS no ano de 2019. Essa proporção foi descontada do total de mortes por todas as causas a cada ciclo.

No caso-base, os pacientes entravam no modelo com 65 anos, considerando a idade média de uma coorte de pacientes brasileiros com AVCi primário atendidos em Joinville (Cabral et al., 2019). Os custos foram expressos em reais (R\$). Foi aplicada taxa de desconto para custos e efetividade de $5 \%$ ao ano em todo o modelo. A perspectiva adotada foi de um terceiro pagador público (Sistema Único de Saúde - SUS).

\section{Utilidades}

Em buscas conduzidas até março de 2020 nas bases de dados PubMed, Lilacs e SciELO, não foram identificadas avaliações de utilidade por nível de incapacidade após AVC no Brasil. Foram utilizados dados de utilidade internacionais, avaliados pelo método time trade-off reunidos em duas revisões sistemáticas sobre estudos de avaliação de utilidade (Post et al., 2001; Tengs \& Lin, 2003). Para mRS 2-3 e 4-5, foram utilizados os valores médios e amplitude de variação estimados em pacientes de risco para AVC, conforme descritos por Post et al. (2001), sendo esses os mesmos valores de utilidade empregados no modelo de Araújo et al. (2010). Para mRS 0-1, foi utilizada a mediana e variação de valores de utilidade em pacientes de risco ou após AVC identificados na revisão de Tengs \& Lin (2003).

A fonte para desutilidade por HICs foi o estudo de Sullivan \& Ghushchyan (2006), estimada em um catálogo de escores avaliados pelo questionário EuroQol 5 dimensions (EQ-5D) para condições crônicas do Medical Expenditure Panel Survey (MEPS, de 2000-2002).

\section{Custos}

Os custos diretos do tratamento de AVCi agudo foram estimados por meio de análise secundária dos dados de uma avaliação prospectiva dos custos associados com o tratamento de AVC em um hospital público de Joinville, utilizando o método de microcusteio (Safanelli et al., 2019). Na análise original, foram incluídos 196 pacientes com AVCi, 41 tratados com trombólise e 134 com tratamento clínico sem trombólise, além de 21 pacientes tratados com trombólise associada à trombectomia no período de 2016 a 2017. No presente estudo, por sua vez, foram considerados apenas os custos de pacientes com AVCi agudo não fatal que receberam tratamento clínico associado à trombólise $(n=38)$ ou apenas tratamento clínico $(n=121)$. Pacientes com AVCi agudo que foram tratados com trombólise associada à trombectomia e pacientes que foram a óbito durante a internação foram excluídos da análise. A exclusão dos óbitos se deve à pequena representatividade na amostra (3 óbitos em pacientes tratados com trombólise e 13 óbitos em pacientes que receberam tratamento clínico), o que instabiliza as médias calculadas. Porém, embora os óbitos tenham sido excluídos, foi considerado relevante representar, ainda que de forma diferente, o custo de internações que culminaram em óbito.

Foi realizada avaliação nos valores médios de Autorizações de Internação Hospitalar (AlHs) reduzidas nos anos de 20172019, para ambos os procedimentos de tratamento do AVCi agudo com uso de trombolítico (03.03.04.030-0) e tratamento de AVC (03.03.04.014-9). Um total de 9.902 AlHs para tratamento com trombolítico e de 583.994 AlHs para tratamento clínico foi identificado para o período analisado. A razão entre custo médio em AlHs com óbito registrado e sem óbito registrado foi de 1,40, 1,67 e 1,45, em 2017, 2018 e 2019, respectivamente, em pacientes tratados com trombolítico, e de 1,85 nos três anos avaliados para tratamento clínico, indicando que o custo em pacientes com óbito durante a internação é consistentemente mais alto do que em pacientes que sobrevivem. A partir desses dados, ficou constatada a importância de aplicar um multiplicador aos dados de casos não fatais da base de Joinville, para estimar o custo esperado de um evento fatal. O multiplicador médio implícito nos dados avaliados nesses anos, 1,51 e 1,85, para tratamento clínico com trombolítico e tratamento clínico sem trombolítico, foi aplicado sobre o custo de AVCi não fatal no modelo, para definir o custo de AVCi fatal.

O custo do medicamento foi obtido na tabela da Câmara de Regulação do Mercado de Medicamentos (CMED), atualizada em maio de 2020, sendo utilizado o Preço de Fábrica das três opções de apresentação de alteplase (50 mg, 20 mg e $10 \mathrm{mg}$ ), considerando ICMS de 0\%, pois alteplase (Actilyse) faz parte de um convênio que isenta ICMS para todos os estados. O custo por paciente foi calculado considerando o peso médio de adultos brasileiros por sexo (Instituto Brasileiro de Geografia e Estatística, 2008) e as unidades de alteplase necessárias para atingir a dosagem preconizada de 0,9 mg/kg.

Os custos crônicos do seguimento dos pacientes (medicamentos e insumos, reinternações por AVC e consultas médicas) e os custos com reabilitação (fisioterapia, fonoaudiologia e/ou 
psicoterapia) também foram obtidos em análise de seguimento de 147 pacientes, acompanhados no Registro de AVC de Joinville (SC) (Safanelli et al., 2019). Os custos do seguimento dos pacientes, exceto para consultas médicas, foram estimados também pelo método de microcusteio e foram computados de acordo com o nível de incapacidade após o AVCi (avaliado na alta hospitalar), categorizando pelas faixas de mRS utilizadas no modelo. Para reabilitação e consultas médicas, os dados de seguimento da coorte apresentavam apenas a frequência de consultas médicas em UBS ou em ambulatório público, assim como a frequência e a duração das terapias de reabilitação. 0 custo foi estimado com os valores de reembolso pelos procedimentos obtidos no Sistema de Gerenciamento da Tabela de Procedimentos, Medicamentos e OPM do SUS (Sigtap), listados na Tabela 3. Custos de seguimento foram aplicados em todos os ciclos, e custos com reabilitação foram aplicados nos primeiros seis meses, conforme dados observados na amostra (tempo de reabilitação máximo de seis meses). Resultados para as análises de custos estão apresentados com os outros parâmetros do modelo na Tabela 4.

Tabela 3. Valores de reembolso por procedimentos utilizados para estimativa de custo com consultas e reabilitação

\begin{tabular}{lc}
\hline Procedimento & Reembolso ambulatorial \\
\hline 03.01.01.007-2 - Consulta médica em atenção especializada & $R \$ 10,00$ \\
\hline 03.01.01.016-1 - Consulta/atendimento domiciliar na atenção especializada & $R \$ 3,14$ \\
\hline $\begin{array}{l}\text { 03.02.06.001-4 - Atendimento fisioterapêutico em pacientes com distúrbios neuro-cinético-funcionais sem } \\
\text { complicações sistêmicas* }\end{array}$ & $R \$ 4,67$ \\
\hline $\begin{array}{l}\text { 03.02.06.002-2 - Atendimento fisioterapêutico em pacientes com distúrbios neuro-cinético-funcionais com } \\
\text { complicações sistêmicas* }\end{array}$ & $R \$ 6,35$ \\
\hline 03.01.07.011-3 - Terapia fonoaudiológica individual & $R \$ 10,90$ \\
\hline 03.01.08.017-8 - Atendimento individual em psicoterapia & $R \$ 2,55$ \\
\hline
\end{tabular}

*Para fisioterapia foi considerado o custo médio dos procedimentos listados (R\$ 5,51)

Tabela 4. Parâmetros do modelo e intervalos de variação utilizados em análises de sensibilidade

\begin{tabular}{|c|c|c|c|}
\hline Variável & $\begin{array}{l}\text { Valor de } \\
\text { referência }\end{array}$ & Intervalo & Fonte \\
\hline Proporção de pacientes atendidos em até 3h dos sintomas* & $50,5 \%$ & 40,4 a $60,6 \%$ & Cougo-Pinto et al., 2012 \\
\hline \multicolumn{4}{|l|}{ Incidência de eventos } \\
\hline \multicolumn{4}{|l|}{ HICs } \\
\hline Controle & $1,27 \%$ & - & Whiteley et al., 2016 \\
\hline Alteplase $(0-4,5 h)$ & $6,68 \%$ & 4,92 a $9,03 \% *$ & Whiteley et al., 2016 \\
\hline \multicolumn{4}{|l|}{ HICs fatal } \\
\hline Controle & $0,41 \%$ & - & Emberson et al., 2014 \\
\hline Alteplase (0-3h) & $4,27 \%$ & 1,03 a $16,02 \%$ & Emberson et al., 2014 \\
\hline Alteplase (3-4,5 h) & $2,26 \%$ & 1,01 a $4,98 \%$ & Emberson et al., 2014 \\
\hline \multicolumn{4}{|l|}{ Desfecho em 90 dias } \\
\hline mRS 0-1 & & & Emberson et al., 2014 \\
\hline Controle & $27,65 \%$ & - & \\
\hline Alteplase (0-3 h) & $40,08 \%$ & 34,03 a $46,45 \%$ & \\
\hline Alteplase (3-4,5 h) & $32,50 \%$ & 28,64 a $36,59 \%$ & \\
\hline mRS 2-3*+ & & & Whiteley et al., 2016 \\
\hline Controle & $24,89 \%$ & - & \\
\hline Alteplase (0-3h) & $19,20 \%$ & - & \\
\hline Alteplase (3-4,5 h) & $25,51 \%$ & - & \\
\hline mRS 4-5*十 & & & Whiteley et al., 2016 \\
\hline Controle & $29,50 \%$ & 19,91 a $29,86 \%$ & \\
\hline Alteplase (0-3 h) & $22,76 \%$ & 15,36 a $23,04 \%$ & \\
\hline Alteplase (3-4,5 h) & $25,51 \%$ & 17,21 a $25,82 \%$ & \\
\hline
\end{tabular}




\begin{tabular}{|c|c|c|c|}
\hline Variável & $\begin{array}{l}\text { Valor de } \\
\text { referência }\end{array}$ & Intervalo & Fonte \\
\hline Morte & & & Emberson et al., 2014 \\
\hline Controle - \% & $17,96 \%$ & & \\
\hline Alteplase (0-3h) & $17,96 \%$ & 14,55 a $22,27 \%$ & \\
\hline Alteplase (3-4,5h) & $20,48 \%$ & 17,06 a $24,43 \%$ & \\
\hline $\begin{array}{l}\text { Risco adicional de morte por todas as causas por nível de } \\
\text { incapacidade }\end{array}$ & & & Fang et al., 2014 \\
\hline mRS 0-1 - HR (IC 95\%) & 1,7 & 1,3 a 2,1 & \\
\hline mRS 2-3 - HR (IC 95\%) & 2,9 & 2,3 a 3,5 & \\
\hline mRS 4-5 - HR (IC 95\%) & 8,3 & 5,2 a 13,2 & \\
\hline AVC reincidente (variável ao longo do tempo) & & & Cabral et al., 2019 \\
\hline Até 6 meses & $2,7 \%$ & 1,2 a $5,1 \%$ & \\
\hline 6 a 12 meses & $2,2 \%$ & 0,9 a $4,4 \%$ & \\
\hline 1 a 2 anos & $4,7 \%$ & 2,7 a $7,7 \%$ & \\
\hline 2 a 3 anos & $4,3 \%$ & 2,3 a $7,2 \%$ & \\
\hline 3 a 4 anos & $2,1 \%$ & 0,8 a $4,5 \%$ & \\
\hline 4 a 5 anos $\neq$ & $0,7 \%$ & 0,1 a $2,5 \%$ & \\
\hline Mortalidade em AVC reincidente* & & & Dantas et al., 2019 \\
\hline $50-59$ anos§ & $18,71 \%$ & 14,97 a $22,45 \%$ & \\
\hline 60-69 anos & $18,85 \%$ & 15,08 a $22,62 \%$ & \\
\hline 70-79 anos & $21,35 \%$ & 17,08 a $25,62 \%$ & \\
\hline$\geq 80$ anos & $27,86 \%$ & 22,29 а $33,43 \%$ & \\
\hline Mortalidade geral por sexo e idade & $1,5-33,7 \%$ & - & IBGE e MPS \\
\hline \% Mortalidade geral devido a AVC reincidente* & & & SIH/SUS 2019 \\
\hline $50-54$ anos§ & $7,37 \%$ & 5,90 a $8,85 \%$ & \\
\hline $55-59$ anos§ & $7,06 \%$ & 5,65 a $8,47 \%$ & \\
\hline 60-64 anos & $7,48 \%$ & 5,98 a $8,98 \%$ & \\
\hline 65-69 anos & $7,41 \%$ & 5,93 a $8,89 \%$ & \\
\hline 70-74 anos & $7,81 \%$ & 6,25 a $9,38 \%$ & \\
\hline 75-79 anos & $8,07 \%$ & 6,46 a $9,69 \%$ & \\
\hline$\geq 80$ anos & $7,16 \%$ & 5,73 a $8,59 \%$ & \\
\hline \multicolumn{4}{|l|}{ Utilidades } \\
\hline mRS 0-1 & 0,76 & 0,73 a 0,93 & Tengs \& Lin, 2003 \\
\hline mRS 2-3 & 0,55 & 0,39 a 0,75 & Post et al., 2001 \\
\hline mRS 4-5 & 0,26 & 0,11 a 0,39 & Post et al., 2001 \\
\hline Desutilidade HICs & $-0,181$ & $-0,145$ a $-0,218$ & Sullivan \& Ghushchyan, 2006 \\
\hline Sexo masculino (\%) & 51,32 & 41,05 a $61,58 \%$ & Dantas et al., 2019 \\
\hline Peso corporal (kg)* & & & IBGE, 2008 \\
\hline Homens & 72,4 & 57,92 a 86,88 & \\
\hline Mulheres & 62,3 & 49,84 a 74,76 & \\
\hline \multicolumn{4}{|l|}{ Custos (R\$) } \\
\hline Custo alteplase* & & & PF CMED, 2020 \\
\hline $50 \mathrm{mg}$ & $2.022,99$ & 1618,39 a 2427,59 & \\
\hline $20 \mathrm{mg}$ & 809,19 & 647,35 a 971,03 & \\
\hline $10 \mathrm{mg}$ & 404,59 & 323,67 a 485,51 & \\
\hline
\end{tabular}




\begin{tabular}{|c|c|c|c|}
\hline Variável & $\begin{array}{l}\text { Valor de } \\
\text { referência }\end{array}$ & Intervalo & Fonte \\
\hline Custo AVC agudo não fatal & & & Safanelli et al., 2019 \\
\hline Controle $(n=121)$ & $7.166,81$ & $6.309,53$ a $8.024,09$ & \\
\hline Alteplase $(n=38)$ & $12.472,35$ & $9.480,50$ a $15.464,21$ & \\
\hline Custo AVC agudo fatal & & & Calculado** \\
\hline Controle & $13.269,30$ & $11.682,06$ a $14.856,55$ & \\
\hline Alteplase & $18.794,01$ & $14.285,73$ a $23.302,30$ & \\
\hline Custo AVC crônico anual & & & Safanelli et al., 2019 \\
\hline mRS 0-1 ( $n=75)$ & $1.118,91$ & 604,59 a $1.633,22$ & \\
\hline$m R S 2-3(n=43)$ & $2.300,84$ & $1.567,68$ a $3.034,01$ & \\
\hline$m R S 4-5(n=29)$ & $9.145,93$ & $5.585,98$ a $12.705,88$ & \\
\hline Custo reabilitação no primeiro semestre & & & Safanelli et al., 2019 \\
\hline mRS 0-1 ( $n=75)$ & 3,33 & 0 a 7,76 & \\
\hline$m R S 2-3(n=43)$ & 32,55 & 6,41 a 58,68 & \\
\hline$m R S 4-5(n=29)$ & 146,04 & 94,19 a 197,90 & \\
\hline
\end{tabular}

* Variação-padrão de 20\% utilizada na ausência de intervalo de confiança para variação em análise de sensibilidade determinística ou probabilística. † Calculada a proporção de pacientes com mRS 2-3 entre os pacientes com mRS 2-5 tratados em até 4,5 h no grupo controle/placebo (45,8\%). Assumida mesma proporção para pacientes em uso de alteplase. ‡ Taxa de reincidência em 4-5 anos foi utilizada para o restante dos anos do modelo. § Dado utilizado apenas no cenário de análise com idade de entrada no modelo de 50 anos. ${ }^{* *}$ Calculado com a aplicação do multiplicador de custo fatal. HICs, hemorragia intracraniana sintomática. IBGE: Instituto Brasileiro de Geografia e Estatística; MPS: Ministério da Previdência Social; mRS: escala Rankin modificada.

\section{Análises de sensibilidade}

Foram conduzidas análises de sensibilidade determinísticas univariadas para identificar incertezas nos parâmetros com maior influência nas estimativas do modelo. Adicionalmente, também foi conduzida análise de sensibilidade probabilística (ASP), com variação de todos os parâmetros randomicamente dentro de suas distribuições estatísticas, sendo conduzidas 1.000 simulações baseadas nos intervalos de confiança de $95 \%$. Assumiu-se que probabilidades e utilidades apresentam distribuição beta, enquanto medidas de associação (HR e OR) apresentam distribuição log-normal e custos apresentam distribuição gama. Para parâmetros em que não houvesse IC 95\%, uma variação padrão de $\pm 20 \%$ foi assumida. Os parâmetros de efetividade de alteplase foram variados dentro do IC 95\% para as medidas de associação descritas na Tabela 4.

Adicionalmente, foram conduzidas análises de cenário, com alteração de fonte de alguns parâmetros do modelo, mantendo os demais parâmetros referentes ao caso-base.
Foram analisados cenários variados para idade de entrada, taxa de reincidência de AVC e fonte de custo do tratamento do AVC, considerando os itens previstos no painel de especialistas descrito por Araújo et al. (2010) e atualizados com os valores atuais da tabela Sigtap.

\section{Resultados}

A Tabela 5 resume os resultados para o caso-base. Considerando o horizonte temporal deste estudo, o tratamento com alteplase em comparação com controle resultou em 0,22 AVG incrementais, 0,32 QALY incrementais e um custo incremental de R\$4.320,12, com RCEl estimada em R\$1 19.996,43/AVG e R\$13.383,64/QALY. A análise dos resultados de acordo com o tempo até o tratamento demonstra melhor RCEl para pacientes tratados em até 3 horas do início dos sinais e sintomas.

Os resultados das análises de cenário, com variação de idade de entrada, taxa de reincidência de AVC e fonte de custo do tratamento do AVC, aparecem na Tabela 6.

Tabela 5. Resultados da análise de custo-efetividade e custo-utilidade no caso base e por faixas de tempo até tratamento

\begin{tabular}{cccccc}
\hline Intervenção & Custos totais (R\$) & AVG & QALY & RCEI (R\$/AVG) & RCEI (R\$/QALY) \\
\hline Controle & $30.498,78$ & 5,25 & 2,99 & & \\
\hline Alteplase & $34.818,90$ & 5,47 & 3,31 & $R \$ 19.996,43$ & $R \$ 13.383,64$ \\
\hline 0-3 h & $34.225,38$ & 5,66 & 3,50 & $R \$ 9.280,59$ & $R \$ 7.367,85$ \\
\hline $3-4,5$ h & $35.424,41$ & 5,28 & 3,13 & $R \$ 183.835,89$ & $R \$ 36.193,27$ \\
\hline
\end{tabular}

AVG: Anos de vida ganhos; QALY: anos de vida ajustados pela qualidade de vida; RCEl: razão de custo-efetividade incremental. 
Tabela 6. Análises de cenário, valores alternativos e resultados

\begin{tabular}{|c|c|c|c|c|}
\hline Variável & Valor & Fonte & RCEI/AVG & RCEI/QALY \\
\hline Caso base & & & $R \$ 19.996,43$ & $R \$ 13.383,64$ \\
\hline Cenário alternativo $\mathbf{A}$ - Idade de entrada & 50 anos & Araújo et al., 2010 & $R \$ 14.164,51$ & $R \$ 5.663,94$ \\
\hline Cenário alternativo B - Idade de entrada & 60 anos & Premissa & $R \$ 17.792,06$ & $\mathrm{R} \$ 10.287,98$ \\
\hline Cenário alternativo C - Idade de entrada & 62 anos & Martins et al., 2020 & $R \$ 18.403,41$ & $\mathrm{R} \$ 11.942,61$ \\
\hline Cenário alternativo D - Idade de entrada & 68 anos & Goulart et al., 2013 & $R \$ 21.574,28$ & $\mathrm{R} \$ 15.637,78$ \\
\hline $\begin{array}{l}\text { Cenário alternativo } \mathbf{E} \text { - Taxa de reincidência de AVC fixa ao longo do } \\
\text { tempo, completando taxa acumulada em } 5 \text { anos }\end{array}$ & $3,27 \%$ & Cabral et al., 2019 & $R \$ 22.152,62$ & $R \$ 14.378,59$ \\
\hline $\begin{array}{l}\text { Cenário alternativo } \mathbf{F} \text { - Taxa de reincidência de AVC fixa ao longo do } \\
\text { tempo, completando taxa acumulada em 1,8 anos }\end{array}$ & $7,68 \%$ & Lange et al., 2018 & $R \$ 30.042,42$ & $\mathrm{R} \$ 18.305,26$ \\
\hline $\begin{array}{l}\text { Cenário alternativo G - Custo AVC agudo não fatal estimado em } \\
\text { atualização do painel de especialistas do estudo de Araújo et al., } 2010 .\end{array}$ & & Araújo et al., 2010 & $\mathrm{R} \$ 1.541,87$ & $\mathrm{R} \$ 1.031,97$ \\
\hline Controle $(R \$)$ & 812,87 & & & \\
\hline Alteplase $(R \$)^{*}$ & 831,62 & & & \\
\hline
\end{tabular}

* Custo com aquisição de alteplase não incluído neste valor.

Em análise de sensibilidade univariada, os fatores com maior impacto sobre as estimativas de RCEI/AVG incluem variações na efetividade de alteplase, custo do tratamento agudo com alteplase, risco adicional de morte em pacientes com mRS 0-1 e proporção de tratados em até 3 horas (Figura 2A). RCEI/QALY foi mais sensível a variações na efetividade de alteplase, custos agudos e crônicos do tratamento de AVCi, utilidade dos estados mRS 0-1 e 2-3 e risco de HIC fatal com alteplase (Figura 2B).

Considerando RCEI/AVG, em 96,6\% das simulações, o tratamento com alteplase representa incremento de custo e incremento de efetividade, e em 0,3\% representa decremento de custo com incremento de efetividade. Considerando um limiar de disposição a pagar (LDP) por AVG ou QALY de 1 PIB per capita para o ano de 2019 (R\$ 31.833,50), 70,7\% das simulações para RCEI/AVG estavam abaixo do LDP (Figura 3A). A partir de um LDP de R\$22.000,00/AVG, a aceitabilidade de alteplase passa a ser superior à do tratamento controle, sendo superior a 80\% em um limiar de R\$ 40.000,00/AVG (Figura 3B).

Para RCEI/QALY, 99,5\% das simulações se encontram no quadrante de custo-efetividade e $0,5 \%$ se encontram no quadrante de dominância, sendo 93,1\% abaixo do LDP presumido (Figura 4A). Considerando um LDP mínimo de R\$ 14.000,00/QALY, a preferência pela alteplase passa a ser maior que pelo controle. A preferência por alteplase é maior que 90\% a partir de um LDP de R\$28.000,00/QALY (Figura 4B).

\section{Discussão}

No presente estudo, o uso de alteplase para tratamento de AVCi, avaliado na perspectiva do SUS no intervalo de 0 a 4,5 horas do início dos sinais e sintomas, foi custo-efetivo, com 70,7\% das simulações abaixo do LDP para AVG e 93,1\% abaixo do LDP para QALY. Embora a análise por tempo até tratamento tenha mostrado a melhor RCEI para pacientes tratados em até 3 horas após o início dos sinais e sintomas, é importante considerar que a janela terapêutica mais curta diminui as chances de tratamento para um grande número de pacientes (Brasil, 2012; Wardlaw et al., 2014). Nos Estados Unidos, a American Heart Association/American Stroke Association atualizou em 2013 as recomendações acerca do uso de alteplase, ampliando o tempo de tratamento para 4,5 horas (Jauch et al., 2013). Na Europa, a European Stroke Organization (ESO) recomendou o uso off label de alteplase até 4,5 horas em 2008/2009, após a disponibilização de novas evidências (Anani et al., 2015). Uma revisão histórica de 20 anos de tratamento trombolítico com alteplase (Campbell et al., 2015) concluiu que, na ausência de contraindicações específicas, a alteplase deve ser administrada na janela de 4,5 horas como padrão.

A escolha por um período mais amplo de tratamento, para além das 3 horas, já foi questionada em função do risco reconhecido de HIC associada ao tratamento trombolítico nas primeiras 48 horas (Emberson et al., 2014). Entretanto, a metanálise com dados individuais de pacientes de Whiteley et al. (2016) mostrou que, embora o melhor desfecho do tratamento com trombolítico esteja associado ao menor intervalo possível entre o aparecimento de sintomas e a administração (assim como à gravidade do evento), a probabilidade de um desfecho ótimo a partir do tratamento no intervalo de 4,5 horas excede o risco de morte. No Brasil, um estudo com pacientes de AVCi grave [escore mediano na escala NIHSS = 16 (10-20)] que receberam trombólise intravenosa em um hospital público até 4,5 horas após o início dos sinais e sintomas de fato não relatou aumento na ocorrência de HIC (CougoPinto et al., 2012). Além disso, um estudo realizado em hospital no estado de Roraima mostrou que, em pacientes sem 
A

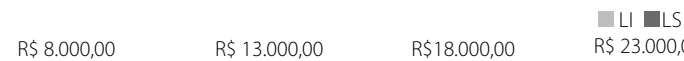

$R \$ 28.000,00 \quad R \$ 33.000,00 \quad R \$ 38.000,00$

$R \$ 43.000,00$

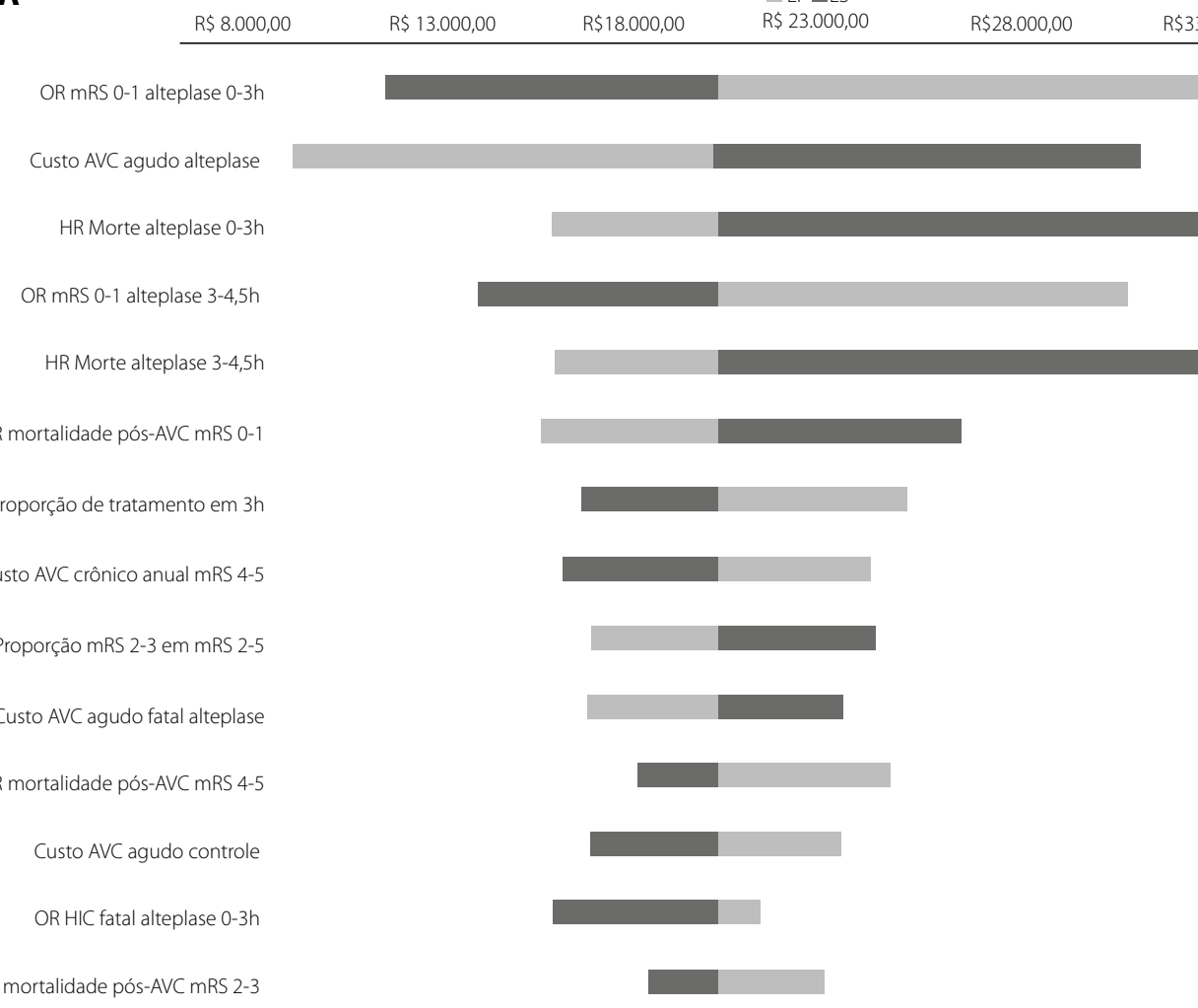

B

LI $\square$ LS

$R \$ 5.000,00$

$R \$ 10.000,00$

$R \$ 15.000,00$

$R \$ 20.000,00$

$R \$ 25.000,00$

OR mRS 0-1 alteplase 0-3h

Custo AVC agudo alteplase

OR mRS 0-1 alteplase 3-4,5h

Custo AVC crônico anual mRS 4-5

Utilidade mRS 0-1

OR HIC fatal alteplase 0-3h

Utilidade mRS 2-3

Custo AVC agudo fatal alteplase

Custo AVC agudo controle

Proporção de tratamento em $3 \mathrm{~h}$

Proporção mRS 2-3 em mRS 2-5

HR mortalidade pós-AVC mRS 0-1

HR mortalidade pós-AVC mRS 4-5

Custo alteplase $50 \mathrm{mg}$
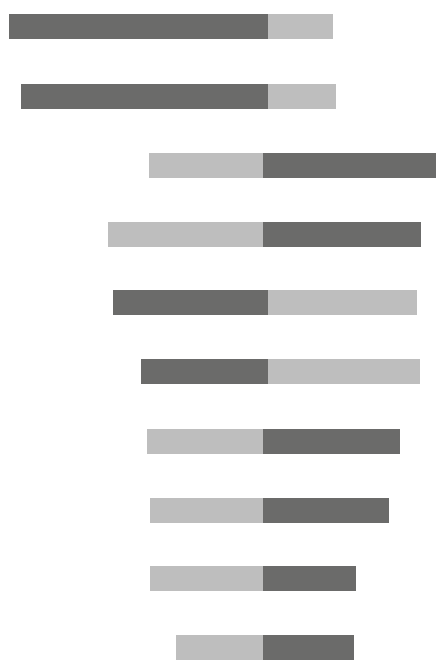

AVC: acidente vascular cerebral; HIC: hemorragia intracraniana; HR: hazard ratio; LI: limite inferior; LS: limite superior; mRS: escala de Rankin modificada; OR: odds ratio.

Figura 2. Gráfico de tornado para análise de sensibilidade univariada sobre A) RCEI/AVG e B) RCEI/QALY. 
A

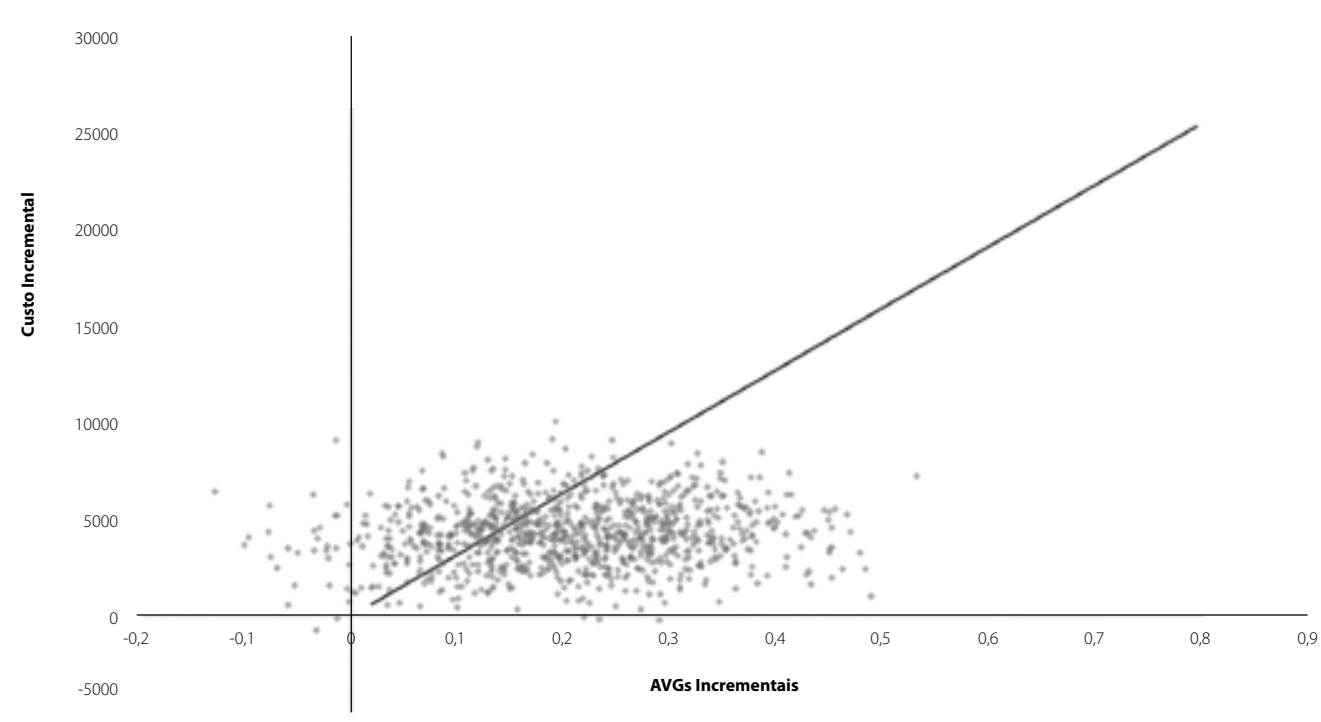

B

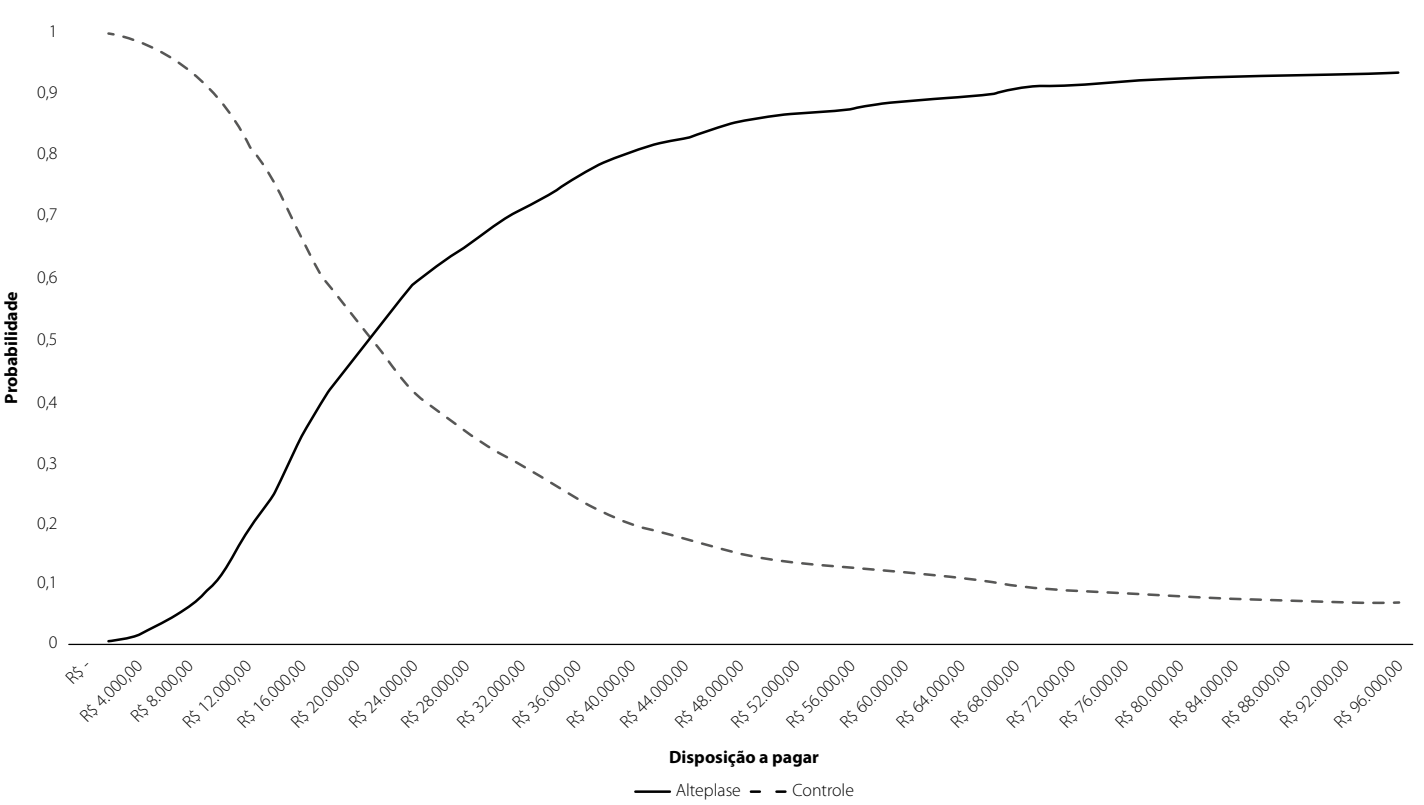

AVG: anos de vida ganhos; LDP: limiar de disposição a pagar; RCEl: razão de custo efetividade incremental.

Figura 3. Resultados da análise de sensibilidade probabilística para RCEI/AVG. A) Gráfico de dispersão para 1.000 simulações e relação com LDP de R\$31.833,50/AVG. B) Curva de aceitabilidade para RCEI/AVG, considerando LDP variáveis.

tratamento trombolítico (Ribeiro Fonseca et al., 2018), o AVCi teve um impacto significativo quanto ao desfecho socioeconômico: na amostra de 50 pacientes adultos, 10 pacientes recebiam benefícios/seguros governamentais antes do AVCi; depois de seis meses do AVCi, esse número subiu para 31. Esses aspectos reforçam a vantagem de estender a possibilidade de tratamento trombolítico ao maior número possível de pacientes, um aspecto mais bem viabilizado pela janela terapêutica de 4,5 horas. Além disso, apesar de evidência positivas, que mostram uma queda na incidência de AVC em todo o mundo, fatores como o envelhecimento populacional e a falta de adesão a medidas preventivas contribuem para uma projeção de aumento no risco de AVC ao longo da vida (Virani et al., 2020).

Vale destacar que o tratamento com trombolítico pelo SUS é restrito a instituições que apresentem recursos apropriados para o atendimento adequado de AVC (Brasil, 2012), as quais estão distribuídas principalmente em regiões metropolitanas e em maior concentração na região Sul e Sudeste do país (Martins et al., 2013). Nesse sentido, a identificação de 
A

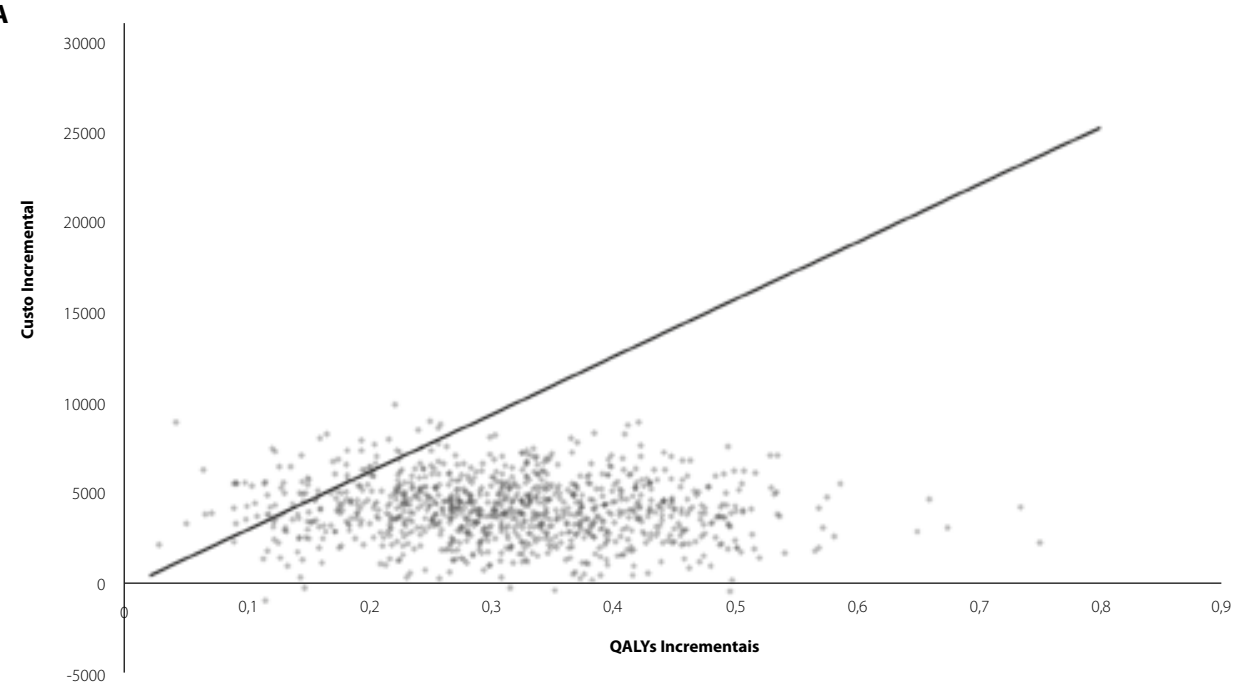

B

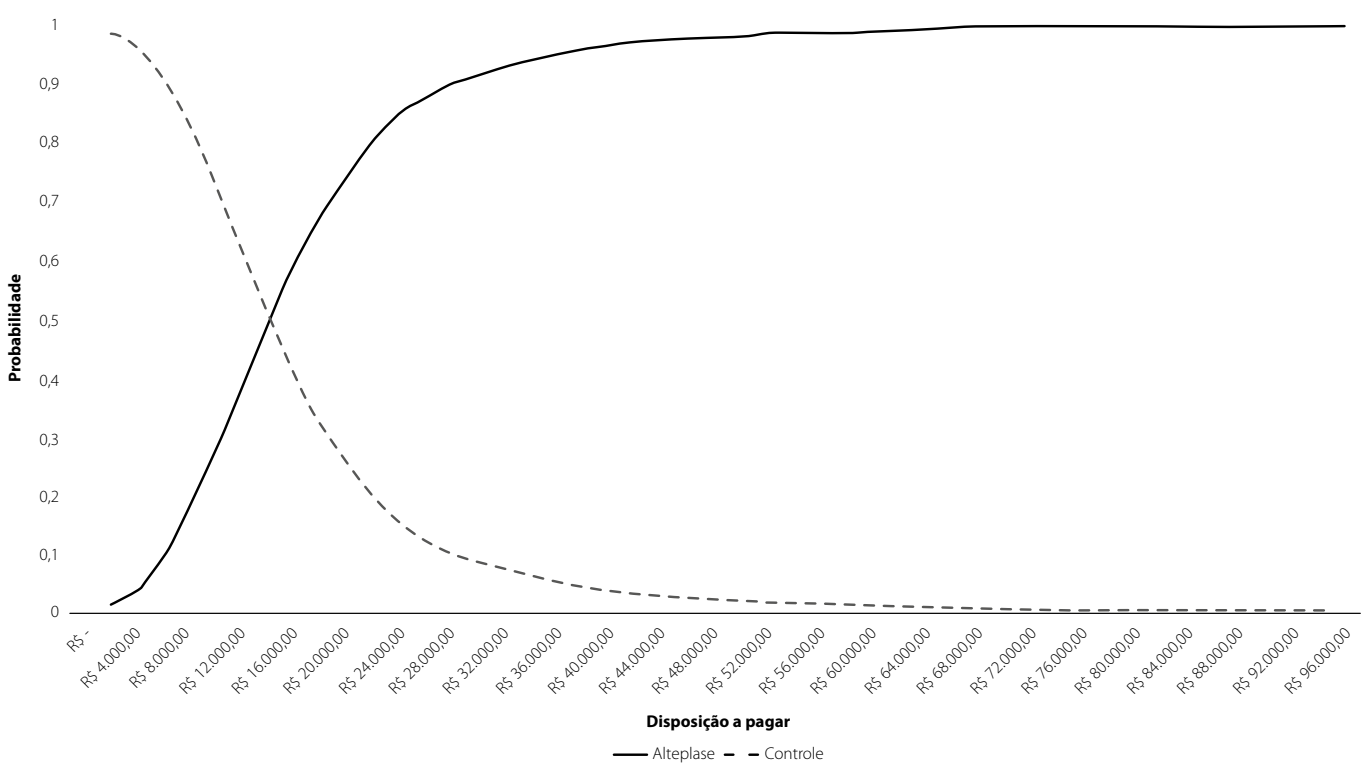

LDP: limiar de disposição a pagar; QALY: anos de vida ajustados pela qualidade de vida; RCEl: razão de custo efetividade incremental.

Figura 4. Resultados da análise de sensibilidade probabilística para RCEI/QALY. A) Gráfico de dispersão para 1000 simulações e relação com LDP de R\$31.833,50/QALY. B) Curva de aceitabilidade para RCEI/QALY, considerando variações no LDP.

uma janela terapêutica mais ampla com garantia de eficácia (Emberson et al., 2014) vai ao encontro da desigualdade de acesso a centros especializados ao cuidado do AVC. Por outro lado, essa desigualdade também representa uma limitação à extrapolação das estimativas apresentadas para algumas regiões com menor acesso à tecnologia.

O custo-utilidade do tratamento com alteplase em até 3 horas na perspectiva do SUS já havia sido demonstrado por Araújo et al. (2010). A estimativa de custos indiretos, por exemplo, ônus pela perda de produtividade, conforme análise de Araújo et al. (2010), é importante para a sociedade, porém pode apresentar grande variabilidade regional e introduzir confusão nas estimativas de custo e custo-efetividade. Ainda, impede a comparação com os resultados de outros estudos que tenham incluído apenas custos diretos, inclusive no contexto brasileiro. Assim, embora seja impraticável a comparação de valores estimados, os resultados do presente estudo vão ao encontro da conclusão de estudo nacional prévio, mesmo com ampliação da janela temporal de tratamento. Nesse sentido, a análise tanto de custo-efetividade (AVG) como de custo-utilidade (QALY), com o uso de dados de custo estimados por microcusteio e ampla variação de parâmetros em análises de sensibilidade, aumenta a confiança nos resultados obtidos. 
Listam-se como pontos fortes deste estudo a avaliação do custo-efetividade da alteplase na janela terapêutica preconizada pelos protocolos clínicos aplicados no Brasil, mas incorporando a diferença de benefício com o tratamento precoce. Adicionalmente, a modelagem foi baseada no desfecho clínico do paciente, considerando o nível de incapacidade resultante desse evento, com custos e qualidade de vida respectivos a esses níveis de incapacidade. Foram utilizadas como fonte de dados clínicos metanálises de dados de pacientes individuais de ensaios clínicos randomizados multinacionais, incluindo milhares de pacientes (Emberson et al., 2014; Whiteley et al., 2016). Entretanto, mesmo sendo uma fonte de evidência robusta da eficácia da intervenção, não representa a efetividade de seu uso em mundo real, uma limitação comum à maioria dos modelos de avaliação de custo-efetividade de medicamentos. Apesar das limitações inerentes à avaliação de custo-efetividade, incluindo a simplificação da realidade necessária à construção de modelos, a utilização de parâmetros baseados em dados da literatura e a falta de dados locais, especialmente de utilidade, as medidas de controle e ajuste foram suficientemente robustas para garantir a aplicabilidade dos resultados em diversos contextos.

\section{Conclusão}

O presente estudo confirmou que o tratamento de AVCi com alteplase em até 4,5 horas após o início dos sinais e sintomas é custo-efetivo na perspectiva do SUS. Entretanto, para garantir que os benefícios desse tratamento sejam estendidos para um número máximo de pacientes, é importante a adesão de todos os serviços de saúde aos protocolos preconizados para o SUS, assim como a conscientização da população quanto à necessidade de procurar atendimento o mais prontamente possível na presença de sintomas que indiquem AVCi.

\section{Referências bibliográficas}

Actilyse ${ }^{\circledast}$ (alteplase). Bula profissional. Boehringer Ingelheim. Anvisa. 2019.

Anani N, Mazya MV, Bill O, Chen R, Koch S, Ahmed N, et al. Changes in European label and guideline adherence after updated recommendations for stroke thrombolysis: Results from the safe implementation of treatments in stroke registry. Circ Cardiovasc Qual Outcomes. 2015;8(6 Suppl 3):S155-62.

Araújo DV, Teich V, Passos RB, Martins SC. Analysis of the cost-effectiveness of thrombolysis with alteplase in stroke. Arq Bras Cardiol. 2010;95(1):12-20.

Boudreau DM, Guzauskas G, Villa KF, Fagan SC, Veenstra DL. A model of cost-effectiveness of tissue plasminogen activator in patient subgroups 3 to 4.5 hours after onset of acute ischemic stroke. Ann Emerg Med. 2013;61(1):46-55.

Brasil. Ministério da Previdência Social. Tábuas de mortalidade IBGE 2018 extrapoladas - MPS. 2019a. Available from: http://www.antigo. previdencia.gov.br/wp-content/uploads/2019/12/Tabuas_de_ Mortalidade_IBGE_2018_Extrapoladas-MPS.xIs

Brasil. Ministério da Saúde. Departamento de Informática do SUS - Datasus. Informações de Saúde (TabNet). Mortalidade geral. Sistema de Informações sobre Mortalidade - SIM. Available from: http://www2. datasus.gov.br/DATASUS/index.php?area=0205. Accessed on: Set 3, 2020.
Brasil. Ministério da Saúde. Departamento de Vigilância de Doenças e Agravos não Transmissíveis e Promoção da Saúde. Saúde Brasil 2018 uma análise de situação de saúde e das doenças e agravos crônicos: desafios e perspectivas. Brasília: Ministério da Saúde; 2019b.

Brasil. Ministério da Saúde. Portaria no 664, de 12 de abril de 2012. Aprova o protocolo clínico e diretrizes terapêuticas - trombólise no acidente vascular cerebral isquêmico agudo. Brasília: Ministério da Saúde; 2012.

Bugarski Ignjatovic V, Semnic M, Gebauer Bukurov K, Kozic D. Cognitive impairment and functional ability in the acute phase of ischemic stroke. Eur Rev Med Pharmacol Sci. 2015;19(17):3251-6.

Cabral NL, Nagel V, Conforto AB, Magalhaes PS, Venancio VG, Safanelli J, et al. High five-year mortality rates of ischemic stroke subtypes: A prospective cohort study in Brazil. Int J Stroke. 2019;14(5):491-9.

Campbell BC, Meretoja A, Donnan GA, Davis SM. Twenty-year history of the evolution of stroke thrombolysis with intravenous alteplase to reduce long-term disability. Stroke. 2015;46(8):2341-6.

Castro LG. Nota técnica sobre a metodologia adotada pelo Ministério da Previdência Social na extrapolação das tábuas de mortalidade IBGE para as idades acima de 80 anos. 2015. Available from: http://www.antigo. previdencia.gov.br/wp-content/uploads/2015/06/NOTA-TECNICAATUARIAL-EXTRAPOLACAO-DA-TABUA-IBGE-MPS.pdf

Cougo-Pinto PT, Santos BL, Dias FA, Fabio SR, Werneck IV, Camilo MR, et al. Frequency and predictors of symptomatic intracranial hemorrhage after intravenous thrombolysis for acute ischemic stroke in a brazilian public hospital. Clinics (Sao Paulo). 2012;67(7):739-43.

de Santana NM, Dos Santos Figueiredo FW, de Melo Lucena DM, Soares FM, Adami F, de Carvalho Pádua Cardoso L, et al. The burden of stroke in Brazil in 2016: An analysis of the global burden of disease study findings. BMC Res Notes 2018;11(1):735.

Emberson J, Lees KR, Lyden P, Blackwell L, Albers G, Bluhmki E, et al. Effect of treatment delay, age, and stroke severity on the effects of intravenous thrombolysis with alteplase for acute ischaemic stroke: A meta-analysis of individual patient data from randomised trials. Lancet. 2014;384(9958):1929-35.

Fagan SC, Morgenstern LB, Petitta A, Ward RE, Tilley BC, Marler JR, et al. Costeffectiveness of tissue plasminogen activator for acute ischemic stroke. Ninds rt-PA stroke study group. Neurology. 1998;50(4):883-90.

Fang MC, Go AS, Chang Y, Borowsky LH, Pomernacki NK, Udaltsova N, et al. Long-term survival after ischemic stroke in patients with atrial fibrillation. Neurology. 2014;82(12):1033-7.

Instituto Brasileiro de Geografia e Estatística - IBGE. Pesquisa de orçamentos familiares, 2008. Tabela 2645 - Estimativas populacionais das medianas de altura e peso de crianças, adolescentes e adultos, por sexo, situação do domicílio e idade - Brasil e grandes regiões. Available from: https:// sidra.ibge.gov.br/tabela/2645.

Jauch EC, Saver JL, Adams HP Jr, Bruno A, Connors JJ, Demaerschalk BM, et al. Guidelines for the early management of patients with acute ischemic stroke: A guideline for healthcare professionals from the american heart association/american stroke association. Stroke. 2013;44(3):870-947.

Lansberg MG, Bluhmki E, Thijs VN. Efficacy and safety of tissue plasminogen activator 3 to 4.5 hours after acute ischemic stroke: A metaanalysis. Stroke. 2009;40(7):2438-41.

Martins SC, Pontes-Neto OM, Alves CV, de Freitas GR, Filho JO, Tosta ED, et al. Past, present, and future of stroke in middle-income countries: The brazilian experience. Int J Stroke. 2013;8 Suppl A100:106-11.

Martins SCO, Weiss G, Almeida AG, Brondani R, Carbonera LA, de Souza AC, et al. Validation of a Smartphone Application in the Evaluation and Treatment of Acute Stroke in a Comprehensive Stroke Center. Stroke. 2020;51(1):240-6. 
National Institute of Neurological Disorders and Stroke rt-PA Stroke Study Group. Tissue plasminogen activator for acute ischemic stroke. N Engl J Med. 1995;333(24):1581-7.

Pan Y, Chen Q, Zhao X, Liao X, Wang C, Du W, et al. Cost-effectiveness of thrombolysis within 4.5 hours of acute ischemic stroke in china. PloS One. 2014;9(10):e110525.

Post PN, Stiggelbout AM, Wakker PP. The utility of health states after stroke: A systematic review of the literature. Stroke. 2001;32(6):1425-9.

Ribeiro Fonseca AR, Murari RSW, Fonseca AJ, Buenafuentes SMF. Impacto socioeconômico do acidente vascular cerebral no estado de Roraima: Um estudo de coorte de base hospitalar. Rev Bras Neurol Psiquiatr. 2018;22(2):124-41.

Safanelli J, Vieira LGDR, Araujo Td, Manchope LFS, Kuhlhoff MHR, Nagel $V$, et al. The cost of stroke in a public hospital in Brazil: A one-year prospective study. Arq Neuro-Psiquiatr. 2019;77(6):404-11.

Sandercock P, Berge E, Dennis M, Forbes J, Hand P, Kwan J, et al. Costeffectiveness of thrombolysis with recombinant tissue plasminogen activator for acute ischemic stroke assessed by a model based on uk nhs costs. Stroke. 2004;35(6):1490-7.

Sinclair SE, Frighetto L, Loewen PS, Sunderji R, Teal P, Fagan SC, et al. Cost-utility analysis of tissue plasminogen activator therapy for acute ischaemic stroke: A Canadian healthcare perspective. PharmacoEconomics. 2001;19(9):927-36.
Sullivan PW, Ghushchyan V. Preference-Based EQ-5D index scores for chronic conditions in the United States. Med Decis Making. 2006;26(4):410-20.

Tengs TO, Lin TH. A meta-analysis of quality-of-life estimates for stroke. PharmacoEconomics. 2003;21(3):191-200.

Tung CE, Win SS, Lansberg MG. Cost-effectiveness of tissue-type plasminogen activator in the 3- to 4.5-hour time window for acute ischemic stroke. Stroke. 2011;42(8):2257-62.

Ullberg T, Zia E, Petersson J, Norrving B. Changes in functional outcome over the first year after stroke: An observational study from the Swedish stroke register. Stroke. 2015;46(2):389-94.

Virani SS, Alonso A, Benjamin EJ, Bittencourt MS, Callaway CW, Carson AP, et al. Heart disease and stroke statistics-2020 update: A report from the American Heart Association. Circulation. 2020;141(9):e139-e596.

Wardlaw JM, Murray V, Berge E, del Zoppo GJ. Thrombolysis for acute ischaemic stroke. Cochrane Database Syst Rev. 2014;2014(7):Cd000213.

Whiteley WN, Emberson J, Lees KR, Blackwell L, Albers G, Bluhmki E, et al. Risk of intracerebral haemorrhage with alteplase after acute ischaemic stroke: A secondary analysis of an individual patient data meta-analysis. Lancet Neurol. 2016;15(9):925-33.

Zou Z, Cini K, Dong B, Ma Y, Ma J, Burgner DP, et al. Time trends in cardiovascular disease mortality across the brics: An age-period-cohort analysis of key nations with emerging economies using the global burden of disease study 2017. Circulation. 2020;141(10):790-9. 